\title{
KEPEMIMPINAN, KARAKTERISTIK PEKERJAAN, PROSPEK KARIR DALAM MEMOTIVASI KERJA KARYAWAN
}

\author{
Sulaimiah $^{1}$, Djoko Suprayetno ${ }^{2}$, Mahyuddin Nasir $^{3}$ \\ ${ }^{1}$ Fakultas Ekonomi dan Bisnis Unram, sulaimiahmia65@gmail.com \\ ${ }^{2}$ Fakultas Ekonomi dan Bisnis Unram, yetno2006@yaho0.com \\ ${ }^{3}$ Fakultas Ekonomi dan Bisnis Unram, mahyuddinnasir@gmail.com

\begin{tabular}{|c|c|c|c|}
\hline \multicolumn{4}{|l|}{ Article history } \\
\hline Dikirim tanggal & : $21 / 02 / 2020$ & Diterima tanggal & $\therefore \quad 8 / 09 / 2020$ \\
\hline Revisi pertama tanggal & $\therefore 02 / 09 / 2020$ & Tersedia online tanggal & $\therefore \quad 29 / 9 / 2020$ \\
\hline
\end{tabular}

\begin{abstract}
ABSTRAK
Penelitian ini bertujuan mengetahui pengaruh signifikan Kepemimpian, ,Karakteritik Pekerjaan dan Prospek karir terhadap motivasi kerja karyawan sub bagian umum dan kepegawaian pada instansi ruang lingkup pemerintahan kabupaten Lombok Timur.Metode penelitian di gunakan dengan metode assosiatif dengan menggunakan sampel sebanyak 51 responden yang di ambil secara random sampeling dengan rumus Slovin yang tersebar di seluruh sub bagian umum dan kepegawaian pada instansi lingkup pemerintahan kabupaten Lombok Timur. Metode pengumpulan data dengan metode angket dan dokumentasi, jenis data yang digunakan adalah data Primer yang di ambil dari tanggapan responden dan sekunder. Alat analisis yang di gunakan adalah regresi berganda dengan uji $\mathrm{F}$ dan uji t serta uji determinan parsial disertai uji validitas dan reliabilitas serta uji asumsi klasik. Hasil penelitian yang didapatkan kepemimpinan, Karakteristik kerjaan dan Prospek karir mempunyai pengaruh signifikan secara parsial. Saran yang bisa di kemukakan berdasarkan hasil penelitian yang sudah di lakukan ini, pemimpin lebih memperhatikan komunikasi yang bisa mempererat kedekatan antara pemimpin dan bawahan sebagai bentuk pendekatan humanis, memberikan penghargaan bagi karyawan yang berprestasi baik secara lisan maupun tertulis. Memberikan pelatihan kepada karyawan agar lebih mengenal pekerjaan dan tuntutan pekerjaan serta memberikan peluang kerja lebih terbuka seperti memberikan promosi jabatan yang lebih transparan sebagai bentuk perwujudan adanya peluang karir yang lebih baik bagi karyawan.

Kata Kunci: Kepemimpinan, Karakteristik Pekerjaan, Prospek Karir, Motivasi Kerja
\end{abstract}

\begin{abstract}
This study aims to determine the significant influence of Leadership, Job Characteristics and Career Prospects on the work motivation of sub-section general employees and staffing on the agency's scope of government in East Lombok district.

The research method is used with an associative method by using a sample of 51 respondents taken by random sampling with Slovin formula scattered throughout the general sub-division and staffing in the East Lombok district government agencies. Data collection method using questionnaire and documentation method, the type of data used is Primary data taken from respondent and secondary responses. The analytical tool used is multiple regression with F-test and t-test and partial determinant test, validity, reliability, and classic assumption test. While the results show Leadership, Job Characteristics, and Career Prospects have a significant effect on Work Motivation, while leadership, work characteristics, and career prospects have a significant partial effect on work motivation. The dominant test with the partial determinant test seen dominant is the Job Characteristics.
\end{abstract}

Key Word: Leadership, Job Characteristics, Career Prospects, Work Motivation 


\section{PENDAHULUAN}

\section{Latar Belakang}

Sumber daya manusia mempunyai peranan yang sangat penting dalam sebuah terhadap Motivasi Kerja organisasi maka diperlukan perhatian yang lebih dari organisasi. Tidak dapat dipungkiri bahwa motif yang mendasari sebagian besar individu bekerja dalam suatu organisasi adalah untuk mencari nafkah dalam memenuhi kebutuhan hidupnya. Individu-individu yang bergabung dalam suatu organisasi menggunakan seluruh pengetahuan, keterampilan, tenaga dan waktunya dengan harapan akan memperoleh penghargaan atas kontribusi yang telah diberikan pada organisasi. Bentuk penghargaan yang menjadi harapan pegawai adalah dalam bentuk kompensasi yang sesuai.

Pemmpinan harus mendorong para karyawan untuk menetapkan tujuan organisasi dalam mengembangkan perencanaan menejemen selanjutnya. Karakteristik pekerjaan juga merupakan faktor yang membentuk kinerja perawat. Karakteristik pekerjaan adalah sifat umum yang diterima oleh pemegang jabatan pekerjaan, baik sifat obyektif atau sifat subyektif, dikaitkan dengan persepsi orang yang mengerjakannya (Gibson, 1997).

Prospek karier yaitu faktor lain yang yang bisa mempengaruhi motivasi laryawan yaitu prospek karir khususnya kesempatan mendapatkan promosi dari pekerjaan yang dilakukan, Menurut Simamora (2006) terjadi tatkala seorang karyawan pindah dari satu pekerjaan ke posisi lain yang lebih tinggi gajinya, tanggung jawabnya dan jenjang operasionalnya.

Motivasi adalah faktor-faktor yang ada dalam diri seseorang yang menggerakan, mengarahkan perilakunya untuk memenuhi tujuan tertentu Menutut Herzberg dalam Suagian 1989,64) di sebut teori dua faktor, yang mengatakan motivasi yang terdiri dari faktor pemeliharaan dan faktor motivasi iru sendiri yaiitu motivasi yang menyangkut dengan kebutuhan psikologogis seseorang yaitu perasaan sempurna dalam melukan pekerjaan yaitu perstasi dalam bekerja, penghargaan, kesempatan berkarir kesuaian dengan minat dan kemampuan serta kompensasi yang di dapat dari pekerjaan tersebut

\section{Tujuan Penelitian}

\section{TUJUAN PENELITIAN}

Beberapa tujuan dari penelitian ini adalah:

1. Untuk mengetahui signifikansi pengaruh Kepemimpinan, Karakteristik Pekerjaan dan prospek karir terhadap Motivasi pegawai secara parsial pada pegawat Sub Bagian dan Kepegawaian pada Insatansi Lingkup Pemerintah Kabupaten Lombok Timur.

2. Untuk mengetahui signifikansi pengaruh Kepemiimpinan, Karakteristik Pekerjaan dan Prospek karier secara simultan terhadap Motivasi pegawai Sub Bagian Umum dan Kepegawaian pada Instansi Lingkup Pemerintah Kabupaten Lombok Timur.

3. Untuk mengetahui variabel yang memiliki pengaruh dominan terhadap Motivasi pegawai Sub Bagian umum dan Kepegawaian pada Instansi Lingkup Pemerintah Kabupaten Lombok Timur. 


\section{Kepemimpinan.}

\section{KEPUSTAKAAN}

Kepemipinan adalah kemampuan untuk mempengaruhi orang lain atau sebuah kelompok untuk mencapai suatu visi atau serangkaian tujuan terentu (Robbin dan Judge 2008; 46), pemimpin dalam menjalankan tugas dengan baik akan memberikan bantuan untuk mencapai tujuan organisasi.

Teori kepemimpinan situasional dari Harsey-Blanchard (dalam Miftah Thoha 1996:64), mengemukakan bahwa gaya kepemimpinan situasional didasarkan atas hubungan antara lain:

1. Kadar hubungan dengan bawahan, memberikan kesempatan mengeluarkan pendapat dan pengarahan yang di berikan oleh pemimpin.

2. Kadar dukungan Susana kerja yang menyenangkan.

3. Tingkat kesiapan dan kemampuan yang di perhatikan dan penghargaan para bawahannya, yang ditunjukkan dalam melaksanakan tugas khusus, fungsi atau tujuan tertentu.

\section{Karakteristik Pekerjaan}

Menurut Kreitner dan Kinicki (2005) menyatakan merupakan karakteristik/cirri yang di temukakan di maing-masing pekerjaan yang berbeda satu sama yang lain, dimana masing-masing organisasi memiliki kebutuhan yang berbeda-beda untuk bisa berkembang lebih cept dan lebih responsip.

Menurut Gibson (1996: 52) menjelaskan lebih lanjut karakteristik inti dari suatu pekerjaan sangat berkaitan dengan pembentukan sikap dan prilaku karyawan terhadap pkerjaan yang dilakukan. Karyawan yang memiliki persamaan persepsi, job disigen serta setting social akan menghasilkan karakteristik pekerjaan sama dan karapun kakteristk ini akan membentuk pengalaman positif, harga diri dan motivasi

\section{Prospek karir}

Pengertian proepek karir menururt Simamora (2006), prospek karir khususnya di sini adalah promosi, tatkala terjadi sesorang pindah dari pekerjaan yang satu ke pekerjaan yang lain dengan level yang lebih tinggi, leboh tinggi gajinya, kemampuannya, propesionalnya setra tanggung jawabnya. Pada umumnya tujuan promosi ini di lakukan untuk memberikan penghargaan dan pengakuan bahwa karyawan yang bersangkutan telah bekerja dengan baik, sehingga menjadi haeapan dan idaman karyawan tersebut/ Motivasi

Abraham Maslow, memngatakan ada 5 kebutuhan manusia yang sifatnya berhirarki, kebutuhan tersebut:

1. Kebutuhan fisiologis atau kebutuhan dasar, yang meliputi sandang, pangan dan papan.

2. Kebutuhan rasa aman

3. Kebutuhan social

4. Kebutuhan penghargaan

5. Kebutuhan aktualisasi diri

Hubungan Kepemimpinan, karakteristik Pekerjaan, Prospek karir dan Motivasi Kerja

Menurut Herzberg dalam Suhardi (2013), factor yang memepengaruhi motivasi seorang karyawan adalah factor internal (kematangan pribadi, dorongan dalam pekerjaan itu sendiri, kepuasan, kebutuhan dan adanya harapan di dalam pekerjaan), sementara factor yang mempengaruhi dari ekternal pekerjaan yaitu yang berasal dari luar pekerjaan, seperti lingkungan, kepemimpinan, patner kerja, peraturan-peraturan. 


\section{Kerangka Konseptual Penelitian}

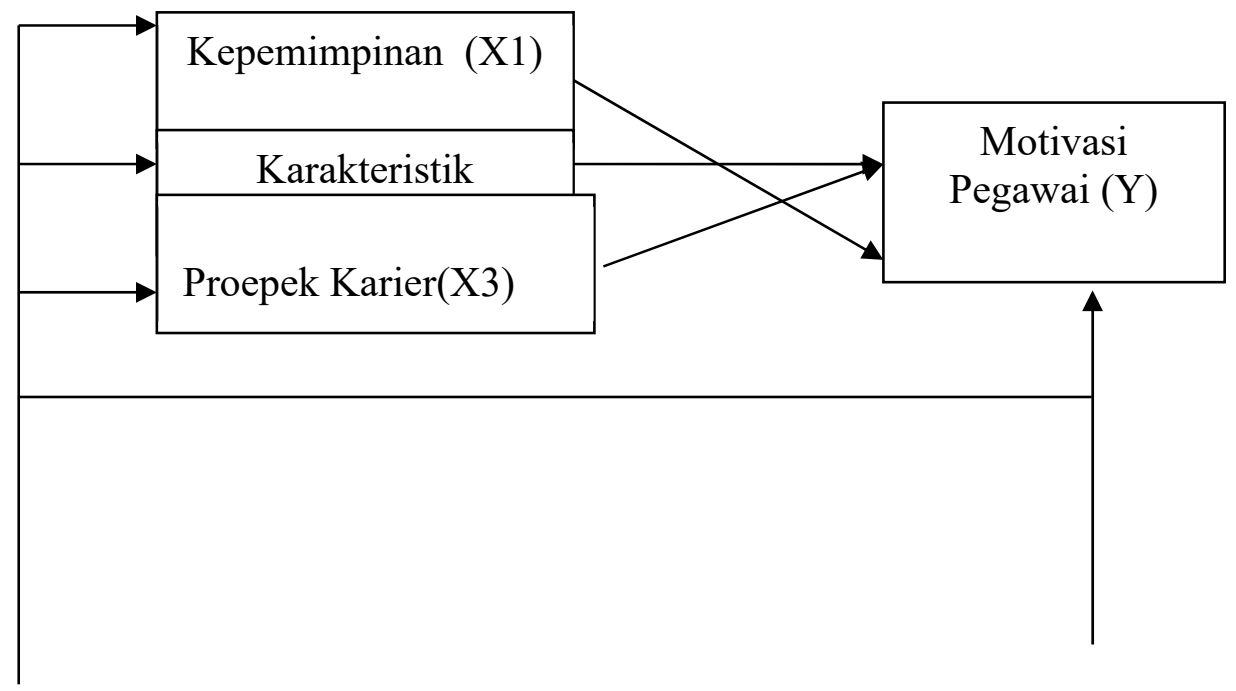

\section{Hipotesis}

1. Di duga pengaruh signifikam kepemimpinan terhadap motivasi kerja pegawai

2. Di duga pengaruh signifikan karakteristik pekerjaan terhadap motivasi kerja pegawai

3. Di duga pengaruh signifikan prospek karir terhadap motivasi kerja pegawai

\section{METODE PENELITIAN}

\section{Jenis Penelitian}

Jenis penelitian yang digunakan dalam penellitian ini adalah penelitian assosiatif.

\section{Metode Pengumpulan Data}

Metode pengumpulan data dalam penelitian ini adalah penelitian sampel yaitu dengan mengambil semua populasi 97 yang akan di gunakan sebagai responden

1. Teknik dan Alat Pengumpulan Data, Metode angket, dokumentetasi dan wawancara, serta alat pengumpulan data adalah kuisioner.

2. Jenis dan Sumber Data, jenis data data kulitatif yang dikuntitatifkan sementara sumber data primer dan sekunder

\section{Identifikasi dan Klasifikasi Variabel}

Berdasarkan permasalahan yang diteliti, maka jumlah variabel pokok yang terkait dapat diidentifikasi sebanyak 3 variabel yang meliputi:

1. Variabel bebas (independen) dalam penelitian ini adalah:

Kepemimpinan, Karakteristik pekerjaan dan Prospek Karier

2. Variabel terikat (dependen) dalam penelitian ini adalah: Motivasi kerja 


\section{Alat anaisis yang digunakan Regresi Linier Berganda}

Untuk menguji hipotesis yang telah diajukan sebelumnya, alat analisis yang digunakan adalah analisis regresi linier berganda sebagai berikut:

$\mathrm{Y}=\mathrm{a}+\mathrm{b} 1 \mathrm{X} 1+\mathrm{b} 2 \mathrm{X} 2+\mathrm{b} 3 \mathrm{X} 3+\mathrm{e}$ dilengkapi uji validitas, relibilitas, uji asumsi klasik, serta uji $\mathrm{F}$ dan uji $\mathrm{t}$

\section{HASIL PENELITIAN DAN PEMBAHASAN}

\section{Identitas Responden}

\section{Tingkat Pendidikan Responden}

Tingkat pendidikan responden dalam penelitian ini bervariasi yaitu yang berada yang berada pada bagian umum dan kepegawaian di intansi lingkup pemerintahan kabupaten Lombok Timur Adapun distribusi responden

terlihat komposisi pendidikan terbanyak adalah tamatan Sekolah menengah atas (47,1\%), diikuti pendidikan S1 (Strata 1) ini menunjukkan tingkat pendidikan yang dimiliki pegawai pada sub bagian umum dan kepegawaian di intansi lingkup pemerintahan kabupaten Lombok timur sudah cukup memadai tapi sudah bisa di katakana pendidikan tinggi lebih dominan, ini bisa dilihat cukup besar porsi strata

\section{Diskripsi Variabel}

\section{Distribusi jawaban responden Variabel Kepemimpinan}

diketahui bahwa responden yang memberikan jawaban dengan rata -rata pada kriteria sesuai yaitu 3,85 ini menunjukkan kepemimpinan yangdi terapkan di lokasi penelitian yaitu sub bagian umum dan kepegawaian di linkup pemerintahan kabupaten Lombok timur sudah sesuai dengan apa yang di harapkan para pegswai dan mereka sudah tahu bagaimnan dan apa yang dinginkan pemimpin mereka.

\section{Variabel Karakteristik Pekerjaan}

Responden yang memberikan jawaban dengan rata-rata tentang stress kerja berada 3,93 yang menunjukkan rata rata karakteritik pekerjaansudah sesuai dengan yang di tuntutan pekerjaan mereka.

\section{Prospek Karier}

Responden yang memberikan jawaban dengan rata-rata pada kriteria sesuai yaitu 3,92 ini menunjukkan prospek karir yang ada di lokasi penelitian yaitu sub bagian umum dan kepegawaian di linkup pemerintahan kabupaten Lombok timur sudah di anggap mejanjikan, dan sesuai dengan keinginanan dan bisa menunjang masa depan mereka.

\section{Motivasi Kerja}

Responden yang memberikan jawaban dengan rata-rata tentang motivasi kerja berada 4.04 yang menunjukkan rata rata motivasi kerja tinggi dalam menyelesaikan pekerjaan yang di bebankan kepada mereka.

\section{Uji Validitas dan Realibelitas}

Uji Validitas, smua item pertanyaan yang adalam kuisioner dari 4 variabel yang di gunakan semuanya valid karena $r$ hitung $>\mathrm{r}$ table 


\section{Uji Reliabilitas}

Pengujian reliabilitas dilakukan dengan menggunakan formula alpha pada program SPSS 20.0 for windows. Instrument dikatakan reliabel atau handal apabila memiliki koefisien reliabilitas $\geq 0,6$ dan sebaliknya

Dari table di atas terlihat semua variabel baik x1, x2, x3 dan Y memiliki alpha cronbach's $>0,6$ yang berarti variabel-variabel tersebut realibel., Semua variable nya menujukkan alpha cronbach $>0,6$ sehingga di nyatakan realibel.

Asumsi Klasik, baik uji Normalitas, uji heterokedasitas, uji Multikolenaritas dan Autokerasi, semua variabelnya memenuhi syarat.

4.5 Uji regeresi

$\mathrm{Y}=\mathbf{0 , 1 3 4}+\mathbf{0 , 1 9 8} \mathrm{X} 1+\mathbf{0 , 5 9 1} \mathrm{X} 2+\mathbf{0 . 2 1 3} \mathrm{X3}$

\section{Uji t (Uji Parsial)}

Uji t (Uji Parsial)

Uji t digunakan untuk mengetahui signifikansi konstanta dari variabel bebas yaitu kepemimpinan (X1), karakteristik Pekerjaan (X2), prospek karir (X3) secara parsial terhadap variabel tikat Motivasi kerja pegawai (Y)

\section{Hasil Analisis Uji t}

Coefficients $^{\mathbf{a}}$

\begin{tabular}{|c|c|c|c|c|c|c|}
\hline & \multirow{2}{*}{$\mathbf{L}$} & \multicolumn{2}{|c|}{ Unstandardized Coefficients } & \multirow{2}{*}{$\begin{array}{c}\begin{array}{c}\text { Standardized } \\
\text { Coefficients }\end{array} \\
\text { Beta }\end{array}$} & \multirow[t]{2}{*}{$\mathbf{T}$} & \multirow{2}{*}{ Sig. } \\
\hline & & B & Std. Error & & & \\
\hline \multirow{4}{*}{1} & (Constant) & .0 .134 & .0 .120 & & .1 .118 & 269 \\
\hline & $\mathrm{X} 1$ &.-241 & .093 & .198 & 2.587 & .013 \\
\hline & $\mathrm{X} 2$ & .624 & .093 & 591. & 6.682 & .000 \\
\hline & $\mathrm{X} 3$ & -.233 & 096 & 213 & -2.432 & 086 \\
\hline
\end{tabular}

Sumber: Primne di olah

Nilai ttabel adalah sebesar 1.675. Berdasarkan hasil uji t pada tabel di atas dapat dilihat bahwa variabel Kepemipinan dan karakteristik pekerjaan dan prospek karir berpengaruh secara signifikan terhadap motivasi kerja karyawan sub bagian umum dan kepegawaian lingkup pemerintahan kabupaten Lombok Timur., semua Varibel berpengaruh signifian secara parsial., ini sesuai dengan teori hezberg yang mengatakan factor-faktor yang mempengaruhi motivasi berassal dari internal pekerjaan dan ekternal pekerjaan ,yang internal yaitu karakteristik pekerjaan, dan prospek karir sementara yang ekternal adalah kepemimpinan 


\section{KESIMPULAN DAN SARAN}

\section{Kesimpulan}

Dari hasil penelitian yang telah dilakukan, dapatl ditarik kesimpulan sebagai berikut:

1. Kepemimpinan yang diterapkan pada instansi sub bagian umum lingkupkapupaten Lomobok timur, mempunyai pengaruh yang positip dan signifikan terhadap motivasi kerja karyawan .

2. Karakteristik pekerjaan berpengaruh signifikan terhadap motivasi kerja karyawan sub bagian umum dan kepegawaian lingkup pemerintahan kabupaten Lombok Timur

3. Prospek karir berpengaruh siterhadap motivasi kerja karyawan sub bagian umum dan kepegawaian lingkup pemerintahan kabupaten Lombok Timur,

4. Kepemimpinan, Karakteritik Pekerjaan, prospek karir secara simultan berpengaruh positip dan signifikan terhadap motivasi kerja karyawan sub bagian umum dan kepegawaian di lingkup pemerintahan kabupaten Lombok Timur

\section{Saran}

1. Memberikan pelatihan-pelatihan di dalam bekerja agar pegawai merasa lebih memahami pekerjaannya.

2. Pemimpin dalam melakukan pengawasan, jangan terlalu ketat, yang mebeumbuat aryawan tidak nyaman di dalam bekerja

3. Pemimpin lebih memberikan penghargaan pada karyawan yang sudah melakukan pekerjaan dengan baik dan benar, dan memberikan prospek karor yang lebih menjanjikan

4. Bagi peneliti selnjutnya lebih banyak lagi meneliti factor-faktor yang mempengaruhi motivasi kerja pegawai seperti temen sejawat, peralatan, kompensasi, lingkungan, dan lainnya.

\section{REFERENSI}

Adianto, Hari. Yuke Agustin, I.G.A. Happy Trindira. 2005. Jurnal Manajemen \& Kewirausahaan, Vol. 7, No. 2, September 2005: 125-138

Adrian Furnham and Andreas Eracleous. 2009. Personality, motivation and job satisfaction: Hertzberg meets the Big Five. Journal of Managerial Psychology Vol. 24 No. 8, pp. $765-779$

Arvey, R.D., Bouchard, T.J., Segal, N.L. and Abraham, L.M. 1989, "Job satisfaction: environmental and genetic components", Journal of Applied Psychology, Vol. 74, pp. 187-92.

Bass, B.M dan Avolio, 1990, The Implications of Transaksional and Transformational, Team and Organization Development, 4, p.231-273

Borchgrevink, C.P. 2004, "Leader-member exchange in a total service industry: the hospitality industry business", in Graen, G.B. (Ed.), New Frontiers of Leadership, Information Age Publishing, Greenwich, CT.

Conger, J.A. 1991. "Inspiring others: the language of leadership", The Executive, Vol. 5, pp. 31-45. 
Dwiyanti, Endang. 2011. Stres Kerja di Lingkungan DPRD: Studi Tentang Anggota DPRD di Kota Surabaya, Malang dan Kabupaten Jember. Jurnal Masyarakat, Kebudayaan dan Politik. Vol 3. p. $73-84$

Vafaei, M. 2000. Teachers' stress: Prevalence, sources, and consequences of occupational stress among primary and secondary school teachers. Psychology Journal, 6(1-2), 63-91.

Farzadfar, F., Hadadi, M., Naeli, J., Haghighi, D., \& Mollashikhi, M. 2005. Performance monitoring of health system managers (1st ed.). Iran's Health Ministry, Tehran: Andishmand.

Gibson J,L IV Ancevich,J.M, James ,H.D (2008) Organisasi,Prilaku, dan Strukuktur ,Proses Jilid 1, Buku Terjemahan ,Jakarta:BinaPura,Aksara.

Goleman, D., Boyatzis, R.E. and McKee, A. 2002. The New Leaders: transforming the Art of Leadership into the Science of Results, Little, Brown, London.

Goleman, D., Boyatzis, R.E. and McKee, A. 2004. Primal Leadership: Learning to Lead with Emotional Intelligence, Harvard Business School Press, Boston, MA, p. 336.

Hamidi Yadollah and Zahra Eivazi. 2010. The Relationships among Employees' Job Stress, Job Satisfaction, and the organizational Performance of Hamadan Urban Health Centers. Social Behavior and Personality, 2010, 38(7), 963-968

Henderson, D.J., Dulac, T. and Liden, R.C. 2006. "The role of LMX and communication in the goal setting process", in Graen, G.B. and Graen, J.A. (Eds), Sharing Network Leadership: LMX Leadership, The Series, Vol. 4, Information Age Publishing, Greenwich, CT, pp. 245-68.

Henderson, D.J., Wayne, S.J., Shore, L.M., Bommer, W. and Tetrick, L.E. 2008. “Leadermember exchange, differentiation, and psychological contract fulfillment: a multilevel examination”, Journal of Applied Psychology, Vol. 93 No. 6, p. 1208.

Herzberg, F., Mausner, B. and Snyderman, B.B. 1959. The Motivation to Work, 2nd ed., John Wiley \& Sons, New York, NY.

Ivancevich, John M., Roberth Konopaske and Michael T. Matteson. 2008. Organizational Behavior and Management. Eight Edition. Mc Graw-Hill International Edition

Johansson G. 2007. The Illness Flexibility Model and Sickness Absence (Doctoral thesis). Karolinska Institutet, Stockholm.

Kramer, M.W. 2006 "Communication strategies for sharing leadership within a creative team: LMX in theater groups", Sharing Network Leadership, LMX Leadership: The Series, Vol. 4, Information Age Publishing, Greenwich, CT, pp. 1-24.

Luthans, Fred. 2006 . Organizational Behavior. New York : McGraw-Hill

Mayfield, J. and Mayfield, M. 2007, “The effects of leader communication on a worker's intent to stay: an investigation using structural equation modeling", Human Performance, Vol. 20 No. 2, pp. 85-102.

Mayfield Jacqueline and Milton Mayfield. 2010. Leader-level influence on motivating language A two-level model investigation on worker performance and job 
satisfaction. Competitiveness Review: An International Business Journal Vol. 20 No. 5, 2010 pp. 407-422

Potu Aurelia. 2013. Kepemimpinan, Motivasi, Dan Lingkungan Kerja Pengaruhnya Terhadap Kinerja Karyawan Pada Kanwil Ditjen Kekayaan Negara Suluttenggo Dan Maluku Utara Di Manado. Jurnal Emba Vol.1 No.4 Desember 2013, Hal. 1208-1218

Sari Rahmila, Mahlia Muis, Nurdjannah Hamid. 2012. Pengaruh Kepemimpinan, Motivasi, Dan Stres Kerja Terhadap Kinerja Karyawan Pada Bank Syariah Mandiri Kantor Cabang Makassar. Diunduh tanggal 5 Februari 2014.http://pasca.unhas.ac.id/jurnal/files/8f8285a8d250d738502b4d19dfdb30c2.p df.

Sulaimiah. 2005. Pengaruh Stressor Individual, Kepribadian Terhadap Stres Kerja Dan Kinerja Karyawan Operasional Perbankan di Mataram Nusa Tenggara Barat. Thesis. Unpublished. Universitas Airlangga. Surabaya

Sulaimiah. Wahidatul Husnaini, Zuhrotul Isnaini, Isnawati dan Wanharul Akbar. 2013 Pengaruh Konflik Peran Ganda Dan Kepemimpinan Terhadap Kinerja Dengan Stress Kerja Sebagai Variabel Intervening. Jurnal Riset Manajemen. Vol 13 No. 1 Maret, p. 21-42

Sullivan, J. (1988), "Three roles of language in motivation theory", Academy of Management Review, Vol. 13 No. 1, pp. 104-15.

Stringer Carolyn Jeni Didham, and Paul Theivananthampillai. 2011. "Motivation, pay satisfaction, and job satisfaction of front-line employees" Qualitative Research in Accounting \& Management Vol. 8 No. 2, 2011pp. 161-179

Solimun. 2007. Memahami Metode Kuantitatif Mutakhir Struktur Equation Modeling \& Partial Least Squere. Modul Pelatihan Pemodelan Persamaan Struktural Pendekatan SEM dan PLS di Universitas Mataram. Juni 2007.

Surati, Sulaimiah, Wahidatul Husnaini, Zuhrotul Isnaini, Rahmat Fakhrurrozi. 2013. Pengaruh Karakteristik Individu, Karakteristik Pekerjaan Dan Dukungan Sosial Terhadap Kepuasan Kerja Dengan Stres Kerja Sebagai Variabel Intervening. Laporan Penelitian. Unpublished. Program Magister Manajemen Universitas Mataram

Raeissi, P., \& Tavakoli, G. H. 2002. The impact of occupational stress on mental health and job performance in hospital managers and matrons. Hakim, 4(5), 247-254.

Van Herpen, M., Van Praag, M. and Cools, K. 2005, "The effects of performance measurement and compensation on motivation: an empirical study", De Economist, Vol. 153 No. 3, pp. 303-29.

Vecchio, Robert, P. 2003. Organizaiotnal Behavior Core Concepts. $5^{\text {th }}$ Edition. Thomson, South Western.

Waluyo, Minto. 2011. Panduan Dan Aplikasi Structural Equation Modelling (Untuk Aplikasi Model Dalam Penelitian Teknik Industri, Psikologi, Sosial dan Manajemen). PT. Indeks. Jakarta 
Yukl, Gary A, 1989. Managerial Leadership: A Review of Theory and Research, Journal of Management, Vol 15, No.2, 251-289.

Zahedi, M. R., Palahang, H., \& Ghafari, M. 2000. Study of job satisfaction of health workers in Charmahal - Bakhtiari Province. Shahrekord University of Medical Sciences, 2(1), 27-33. 